\title{
The red distribution width and the platelet distribution width as prognostic predictors in gastric cancer
}

\author{
Shiqing Cheng, Fuyan Han, Yong Wang, Yanqiu Xu, Teng Qu, Ying Ju* and Zhiming Lu*
}

\begin{abstract}
Background: Increasing attention is focused on the relationship of inflammation biomarkers with malignant tumors. The purpose of the present study was to detect whether the preoperative the red distribution width (RDW) and the platelet distribution width (PDW) can be used to distinguish patients with gastric cancer (GC) or early stage GC from the healthy controls and predict the progression and prognosis of the GC.

Methods: The RDW and PDW values of 227 patients with GC and 164 patients with early GC were retrospectively analyzed comparing with 101 healthy controls. In addition, the clinicopathological features, survival curves and prognosis of the patients with GC were compared between the high and low groups according to the RDW and PDW values.

Results: Significant higher RDW and lower PDW were detected in patients with GC and early GC compared to the healthy controls. A higher RDW was significantly associated with older age, a larger tumor diameter, deeper tumor infiltration, and lymph node metastasis while a lower PDW was significantly associated with male, older age, a larger tumor diameter, deeper tumor infiltration, elevated CEA and CA125. Increased RDW was significantly associated with worse overall survival (OS) and disease-free survival (DFS) for GC ( $P=0.042$ and $P=0.033$, respectively) and early GC ( $P=0.037$ and $P=0.009$, respectively) while decreased PDW indicated a significantly association with poor DFS for early GC $(P=0.006)$. Univariate and multivariate survival analysis showed that RDW and PDW can act as independent prognostic factors for DFS ( $P=0.028$ and $P=0.020)$ in patients with early GC.
\end{abstract}

Conclusion: The preoperative RDW and PDW were simple and convenient predictive factors for the progression and prognosis of patients with GC.

Keywords: Red distribution width, Platelet distribution width, Gastric cancer, Early stage gastric cancer

\section{Background}

Gastric cancer (GC) is still one of the most common causes of cancer-related death despite improvements in treatment modalities worldwide [1]. The incidence rate of gastric cancer varies widely in different areas and is particularly common in East Asia [2]. Most patients are diagnosed at the advanced stage and have either regional or distant metastasis with the 5-year survival less than $10 \%$ [3]. Therefore, it is important to identify prognostic factors for these patients in order to select appropriate treatment for patients. Both

\footnotetext{
*Correspondence: juying2003@126.com; luzhiming@sdu.edu.cn Department of Laboratory Medicine, Shandong Provincial Hospital Affiliated to Shandong University, Jinan, Shandong 250021, China
}

genetic and environmental factors are related to GC development [4]. Previous studies have verified the relationship between inflammation and progress of gastric carcinoma [5-7]. It is well known that cancer can induce malnutrition and chronic inflammatory response, and cancer-related inflammation is a critical factor for progression and prognosis of many cancers $[7,8]$. In recent years, there is a growing interest in establishing novel non-invasive predictive biomarkers from hematological and serologic parameters for various inflammatory diseases and cancers. Although complete blood count $(\mathrm{CBC})$ have been routinely available to clinicians, the roles of several parameters in the 
diagnosis and management of patients with malignancies, such as RDW and PDW, remain obscure.

Red blood cell distribution width (RDW) is widely used laboratory parameter for anemia [9]. However, recent studies have reported that RDW can be used laboratory parameter for inflammatory diseases and cancers, such as atherosclerosis, inflammatory bowel diseases, breast cancer and lung cancer [10-13]. Platelet distribution width (PDW) is a measure of variation in platelet size and a direct flow cytometric measurement of platelet cell volume. PDW has been evaluated as a marker of platelet morphology and activation $[14,15]$. Recent studies also showed the association of PDW with CBC and CRP which indicated the wide relation between platelets and inflammation [16].

However, to the best of our knowledge, there were few specific studies comprehensively evaluating the values of RDW and PDW indices in GC patients. We, therefore, aimed to determine whether the two parameters could be indicators used for assessment of disease diagnosis and prognosis by retrospectively analyzing the correlation between the values of RDW, PDW and the clinical data of GC patients.

\section{Methods}

\section{Subjects}

All clinicopathological data was analyzed retrospectively in 227 patients with GC undergoing radical surgery resection and 101 healthy volunteers as controls which were recruited in Shandong Provincial Hospital Affiliated to Shandong University from July 2010 to December 2014. Furthermore, we collected 164 patients with early stage (T1 stage) GC for comparative analysis with the healthy controls. All patients with histopathologically diagnosed as gastric cancer by two pathologists after a radical resection were selected. Patients were selected for the present study according to the following inclusion criteria: confirmed histopathologic diagnosis; complete whole blood count before surgery; clinicopathological and follow-up data.

The patients with clinical signs of infection, hematologic disease, anaemia, liver disease, with blood transfusion made in the last three months, venous thrombosis detected in the last six months, severe coronary heart disease, autoimmune disease and a history of other malignancies were excluded from the study. A total of $42 \mathrm{pa}-$ tients were excluded due to the criteria in question in our study. Clinicopathological parameters were obtained from medical records. All patients were regularly followed up by telephone interviews and the last follow-up assessment was conducted in November 2016. All patients were staged according to the criteria of American Joint Committee on Cancer Staging (7th edition) [17]. As the primary study end point, overall survival (OS)was calculated from the date of surgery to death from any cause.
The secondary end point was disease-free survival (DFS), which was defined as the time from surgery to identification of disease recurrence, either radiological or histological. Approval for the study was granted by the Ethics Committee of the Shandong Provincial Hospital Affiliated to Shandong University with written informed consents from all participants.

\section{Blood sampling}

RDW and PDW values of patients were detected one week before radical surgery with an automated hematology analyzer XE-2100 (Sysmex, Kobe, Japan). Tumor biomarkers such as carcinoembryonic antigen (CEA) and carbohydrate antigen 199 (CA199) were measured within one month before surgery using a Cobas e601 analyzer (Roche Diagnostics, Mannheim, Germany). We calculated the median values of RDW and PDW in all 227 patients and 164 patients at early stage respectively (13 and $11.5 \%$ in all 227 patients, 12.85 and $11.95 \%$ in 164 patients at early stage). These median values were used as cutoff values of RDW and PDW to classify patients as high and low groups.

\section{Statistical analysis}

Statistical analysis was performed by using SPSS statistical soft ware version 19.0 (SPSS Inc., Chicago, USA). The normal distributions of continuous variables were shown as mean $\pm \mathrm{SD}$ while the non-normal distributions of continuous variables were presented as media$\mathrm{n}$ (interquartile range). Categorical variables were shown as frequencies. While the mean differences between groups were compared by Student's t test, otherwise, Mann Whitney U test was applied for comparisons of the median values. Differences between categories of each clinicopathological feature were analyzed using the chi-squared test. ROC curves were used to determine the diagnostic value of the RDW and PDW. We used the Kaplan-Meier analysis to calculate the OS and DFS rates and the log-rank test to compare the survival rate curves. Significant parameters for survival in univariate analysis were introduced into multivariate Cox proportional hazards model to determine independent prognostic factors. $P$ value $<0.05$ was considered statistical significance.

\section{Results}

\section{Comparison of RDW and PDW values between patients with GC and healthy controls}

The mean \pm SD of preoperative RDW in 227 GC patients and healthy controls were $(13.57 \pm 1.804) \%$ and $(12.80 \pm 0.712) \%$, respectively. The difference was significant $(t=4.137, P<0.001$, Fig. 1a). Likewise, a significant difference existed in PDW value. The mean \pm SD of preoperative $\mathrm{PDW}$ in patients was 

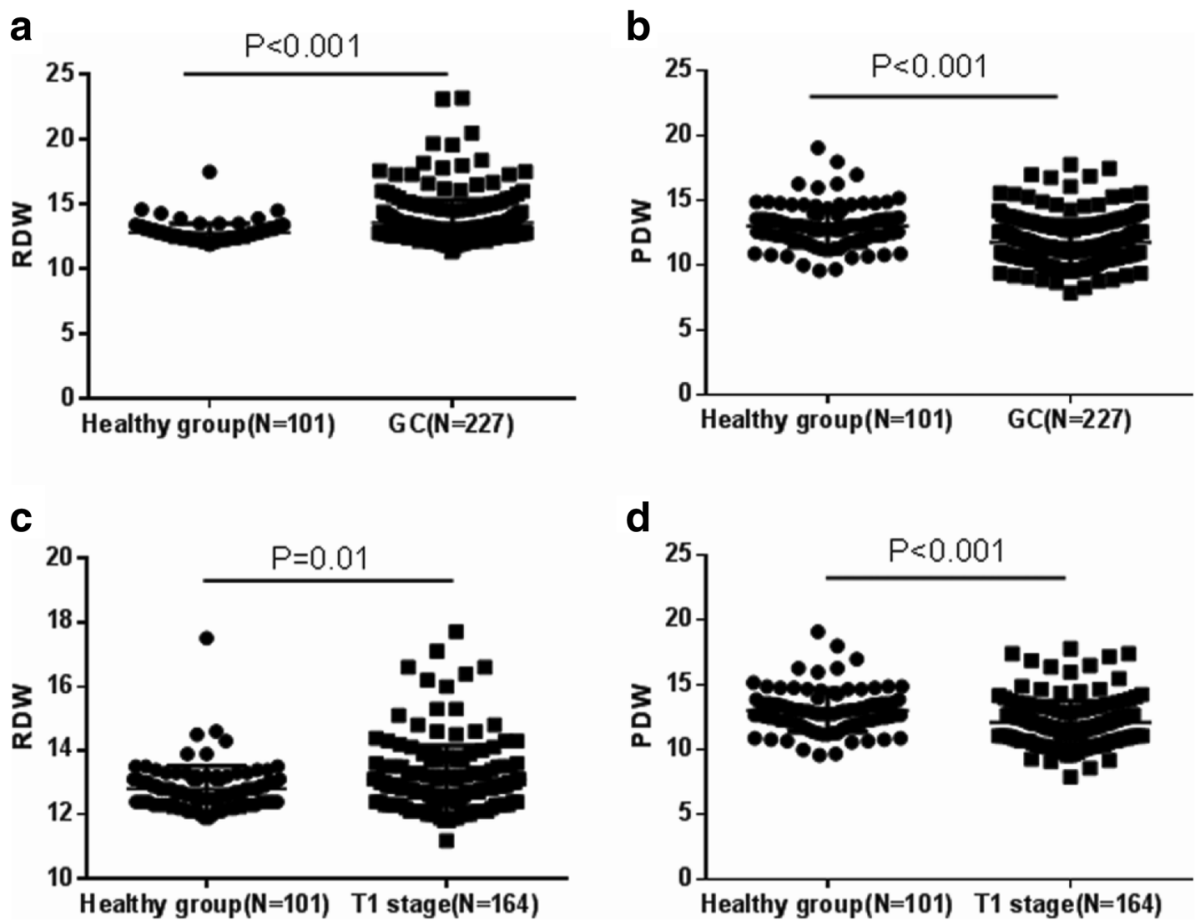

Fig. 1 Comparison of RDW and PDW values between patients with GC and healthy controls. a RDW values between patients with GC and healthy controls. b PDW values between patients with GC and healthy controls. $\mathbf{c}$ RDW values between patients with early stage GC and healthy controls. $\mathbf{d}$ PDW values between patients with early stage GC and healthy controls

$(11.80 \pm 1.733) \%$ which was significantly lower than $(13.03 \pm 1.619) \%$ in healthy controls $(t=6.019, P<0.001$, Fig. 1b). We also calculated the mean \pm SD of RDW and PDW in 164 patients with early stage GC, which were $(13.11 \pm 1.050) \%$ and $(12.11 \pm 1.698) \%$, respectively and there were significant differences comparing to healthy controls $(t=2.578, P=0.010$ and $t=4.337, P<0.001$, respectively, Fig. 1c, d).
ROC curves analysis results

We used ROC curve analysis to verify the predictive power of RDW and PDW in predicting presence of GC and early stage GC. For GC, the AUC of RDW was $0.635(95 \% \mathrm{CI}=0.575-0.695, P<0.001)$ and the AUC of PDW was $0.715(95 \% \mathrm{CI}=0.679-0.785, P<0.001)$ for predicting the presence of GC (Fig. 2a). While for early stage GC, the AUC of RDW and PDW was 0.585
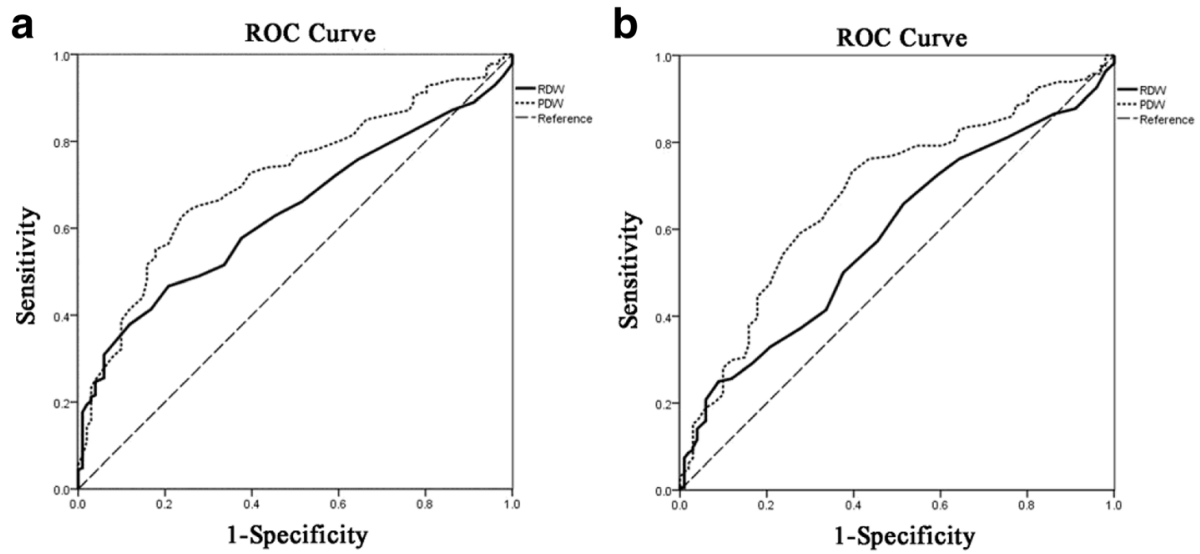

Fig. 2 The results of ROC curve analysis for the predictive power of RDW and PDW in predicting presence of GC and early stage GC. a ROC curve of RDW and PDW in predicting presence of GC. $\mathbf{b}$ ROC curve of RDW and PDW in predicting presence of early stage GC 
$(95 \% \mathrm{CI}=0.516-0.654, \quad P=0.020)$ and $0.683 \quad(95 \% \mathrm{CI}=$ $0.618-0.749, P<0.001)$, respectively, for predicting the presence of early stage GC (Fig. 2b).

\section{Relationships between RDW, PDW and clinicopathological characteristics}

The differences of clinicopathological characteristics between the two groups in $227 \mathrm{GC}$ patients according to RDW and PDW were exhibited in Table 1. A higher
RDW was significantly associated with older age, a larger tumor diameter, deeper tumor infiltration, and Lymph node metastasis $(P<0.001, P=0.001, P=0.008$ and $P=0.014$, respectively). A lower PDW was significantly associated with male, older age, a larger tumor diameter, deeper tumor infiltration, elevated CEA and CA125 $(P=0.039, P=0.007, P=0.005, P=0.047, P=0.004$ and $P=0.041$, respectively). The differences of clinicopathological characteristics between the two groups according

Table 1 Comparison of clinicopathological parameters of 227 patients with GC between high and low groups in terms of RDW and PDW

\begin{tabular}{|c|c|c|c|c|c|c|c|}
\hline Characteristics & Cases (n) & RDW < 13 n(\%) & RDW $\geq 13$ n(\%) & $P$ value $^{a}$ & PDW < $11.5 \mathrm{n}(\%)$ & PDW $\geq 11.5$ n(\%) & $P$ Value $^{\mathrm{a}}$ \\
\hline Gender & & & & 0.467 & & & 0.039 \\
\hline Male & 176 & $83(75.5)$ & $93(79.5)$ & & $91(83.5)$ & $85(72.0)$ & \\
\hline Female & 51 & $27(24.5)$ & $24(20.5)$ & & $18(16.5)$ & $33(28.0)$ & \\
\hline Age(years) & & & & $<0.001$ & & & 0.007 \\
\hline$<60$ & 119 & $76(69.1)$ & $43(36.8)$ & & $47(43.1)$ & $72(61.0)$ & \\
\hline$\geq 60$ & 108 & $34(30.9)$ & $74(63.2)$ & & $62(56.9)$ & $46(39.0)$ & \\
\hline Tumor diameter (cm) & & & & 0.001 & & & 0.005 \\
\hline$\leq 4$ & 101 & $61(55.5)$ & $40(34.2)$ & & $38(34.9)$ & 63(53.4) & \\
\hline$>4$ & 116 & $49(44.5)$ & $77(65.8)$ & & $71(65.1)$ & $55(46.6)$ & \\
\hline Differentiation & & & & 0.569 & & & 0.785 \\
\hline Well & 7 & $3(2.7)$ & $4(3.4)$ & & $3(2.8)$ & $4(3.4)$ & \\
\hline Moderate & 71 & $31(28.2)$ & $40(34.2)$ & & $32(29.4)$ & $39(33.1)$ & \\
\hline Poor & 149 & $76(69.1)$ & $73(62.4)$ & & $74(67.9)$ & $75(63.6)$ & \\
\hline Depth of tumor & & & & 0.008 & & & 0.047 \\
\hline $\mathrm{T} 1+\mathrm{T} 2$ & 64 & $40(36.4)$ & $24(20.5)$ & & $24(22.0)$ & 40(33.9) & \\
\hline $\mathrm{T} 3+\mathrm{T} 4$ & 163 & 70(63.6) & $93(79.5)$ & & $85(78.0)$ & $78(66.1)$ & \\
\hline Lymph node metastasis & & & & 0.014 & & & 0.085 \\
\hline NO & 73 & $44(40.0)$ & $29(24.8)$ & & 29(26.6) & 44(37.3) & \\
\hline $\mathrm{N} 1+\mathrm{N} 2+\mathrm{N} 3$ & 154 & $66(60.0)$ & $88(75.2)$ & & $80(73.4)$ & $74(62.7)$ & \\
\hline Distance metastasis & & & & 0.257 & & & 0.417 \\
\hline MO & 194 & $91(82.7)$ & 103(88.0) & & $91(83.5)$ & 103(87.3) & \\
\hline M1 & 33 & 19(17.3) & 14(12.0) & & 18(16.5) & $15(12.7)$ & \\
\hline pStage & & & & 0.111 & & & 0.131 \\
\hline $1+\|$ & 83 & $46(41.8)$ & $37(31.6)$ & & $36(33.1)$ & 47(39.8) & \\
\hline$I I I+I V$ & 144 & $64(58.2)$ & $80(68.4)$ & & $73(66.9)$ & $71(60.2)$ & \\
\hline CEA(ng/ml) & & & & 0.250 & & & 0.004 \\
\hline$\leq 5$ & 188 & $92(87.6)$ & $96(82.1)$ & & 83(78.3) & 105(92.1) & \\
\hline$>5$ & 34 & $13(12.4)$ & $21(17.9)$ & & $23(21.7)$ & $9(7.9)$ & \\
\hline CA125(U/ml) & & & & 0.553 & & & 0.041 \\
\hline$\leq 35$ & 181 & 85(94.4) & $96(92.3)$ & & 86(89.6) & 95(96.9) & \\
\hline$>35$ & 13 & $5(5.6)$ & $8(7.7)$ & & 10(10.4) & $3(3.1)$ & \\
\hline CA199(U/ml) & & & & 0.563 & & & 0.637 \\
\hline$\leq 39$ & 183 & $84(85.7)$ & $99(88.4)$ & & $86(86.0)$ & $97(88.2)$ & \\
\hline$>39$ & 27 & $14(14.3)$ & 13(11.6) & & $14(14.0)$ & 13(11.8) & \\
\hline
\end{tabular}

Abbreviations: RDW red blood cell distribution width, PDW platelet distribution width, CEA carcinoembryonic antigen, CA125 carbohydrate antigen 125, CA199 carbohydrate antigen 199

avalue was calculated by $x^{2}$ test 
to RDW and PDW in 164 patients with early stage GC were showed in Table 2. A high RDW was only significantly associated with older age. However, no prominent difference existed in other features.

\section{Associations of RDW and PDW with survival of GC}

To investigate whether the RDW and PDW were associated with survival of GC, we performed Kaplan-Meier curves for OS and DFS for all GC (Fig. 3) and early stage GC (Fig. 4). For the 227 patients with GC, the median follow-up duration was 61 months with a range of 1 to
76 months and for the 164 patients with early stage GC, the median follow-up duration was 45 months with a range of 6 to 76 months. A high RDW showed a worse OS $(P=0.042)$ and a shorter DFS $(P=0.033)$ in $227 \mathrm{GC}$ while PDW had no significant association with OS and DFS $(P=0.263$ and $P=0.356$, respectively). For 164 early stage $\mathrm{GC}$, significantly worse $\mathrm{OS}(P=0.037)$ and DFS $(P=0.009)$ were also seen in patients with high RDW group than those with low RDW group. Furthermore, the low PDW group exhibited a poorer DFS than the high group $(P=0.006)$.

Table 2 Comparison of clinicopathological characteristics of 164 patients with GC at early stage between high and low groups in terms of RDW and PDW

\begin{tabular}{|c|c|c|c|c|c|c|c|}
\hline Characteristics & Cases (N) & RDW $<12.85 \mathrm{n}(\%)$ & RDW $\geq 12.85$ n(\%) & $P$ value $^{a}$ & PDW < 11.95 n(\%) & $P D W \geq 11.95$ n(\%) & $P$ Value $^{a}$ \\
\hline Gender & & & & 1.000 & & & 0.711 \\
\hline Male & 126 & $63(76.8)$ & $63(76.8)$ & & $64(78.0)$ & $62(75.6)$ & \\
\hline Female & 38 & 19(23.2) & 19(23.2) & & 18(22.0) & $20(24.4)$ & \\
\hline Age(years) & & & & 0.008 & & & 0.271 \\
\hline$<60$ & 73 & $45(54.9)$ & $28(34.1)$ & & $33(40.2)$ & $40(48.8)$ & \\
\hline$\geq 60$ & 91 & $37(45.1)$ & $54(65.9)$ & & 49(59.8) & $42(51.2)$ & \\
\hline Tumor diameter (cm) & & & & 0.732 & & & 0.732 \\
\hline$\leq 4$ & 155 & 77(93.9) & 78(95.1) & & 77(93.9) & 78(95.1) & \\
\hline$>4$ & 9 & $5(6.1)$ & $4(4.9)$ & & $5(6.1)$ & $4(4.9)$ & \\
\hline Differentiation & & & & 0.437 & & & 0.537 \\
\hline Well & 21 & $12(14.6)$ & $9(11.0)$ & & 11(13.4) & 10(12.2) & \\
\hline Moderate & 74 & $33(40.2)$ & $41(50.0)$ & & $40(48.8)$ & $34(41.5)$ & \\
\hline Poor & 69 & $37(45.1)$ & $32(39.0)$ & & $31(37.8)$ & $38(46.3)$ & \\
\hline Lymph node metastasis & & & & 0.392 & & & 0.200 \\
\hline NO & 138 & $67(81.7)$ & $71(86.6)$ & & 72(87.8) & $66(80.5)$ & \\
\hline $\mathrm{N} 1+\mathrm{N} 2+\mathrm{N} 3$ & 26 & $15(18.3)$ & $11(13.4)$ & & $10(12.2)$ & $16(19.5)$ & \\
\hline Distance metastasis & & & & 0.053 & & & 0.246 \\
\hline MO & 157 & 76(92.7) & $81(98.8)$ & & 80(97.6) & 77(93.9) & \\
\hline M1 & 7 & $6(7.3)$ & $1(1.2)$ & & $2(2.4)$ & $5(6.1)$ & \\
\hline pStage & & & & 0.053 & & & 0.246 \\
\hline $\mid+\|$ & 157 & $76(92.7)$ & $81(98.8)$ & & $76(92.7)$ & 70(85.4) & \\
\hline$I I I+I V$ & 7 & $6(7.3)$ & $1(1.2)$ & & $6(7.3)$ & $12(14.6)$ & \\
\hline CEA(ng/ml) & & & & 0.110 & & & 0.384 \\
\hline$\leq 5$ & 134 & $67(93.1)$ & $67(98.5)$ & & 65(94.2) & 69(97.2) & \\
\hline$>5$ & 6 & $5(6.9)$ & $1(1.5)$ & & $4(5.8)$ & $2(2.8)$ & \\
\hline CA125(U/ml) & & & & 0.955 & & & 0.504 \\
\hline$\leq 35$ & 75 & $36(97.3)$ & $39(97.5)$ & & 33(100.0) & $42(95.5)$ & \\
\hline$>35$ & 2 & $1(2.7)$ & $1(2.5)$ & & $0(0.0)$ & $2(4.5)$ & \\
\hline CA199(U/ml) & & & & 0.563 & & & 0.117 \\
\hline$\leq 39$ & 183 & $84(85.7)$ & $99(88.4)$ & & $64(95.5)$ & $69(100.0)$ & \\
\hline$>39$ & 27 & $14(14.3)$ & 13(11.6) & & $3(4.5)$ & $0(0.0)$ & \\
\hline
\end{tabular}

Abbreviations: RDW red blood cell distribution width, PDW platelet distribution width, CEA carcinoembryonic antigen, CA125 carbohydrate antigen 125 , CA199 carbohydrate antigen 199

aalue was calculated by $x^{2}$ test 

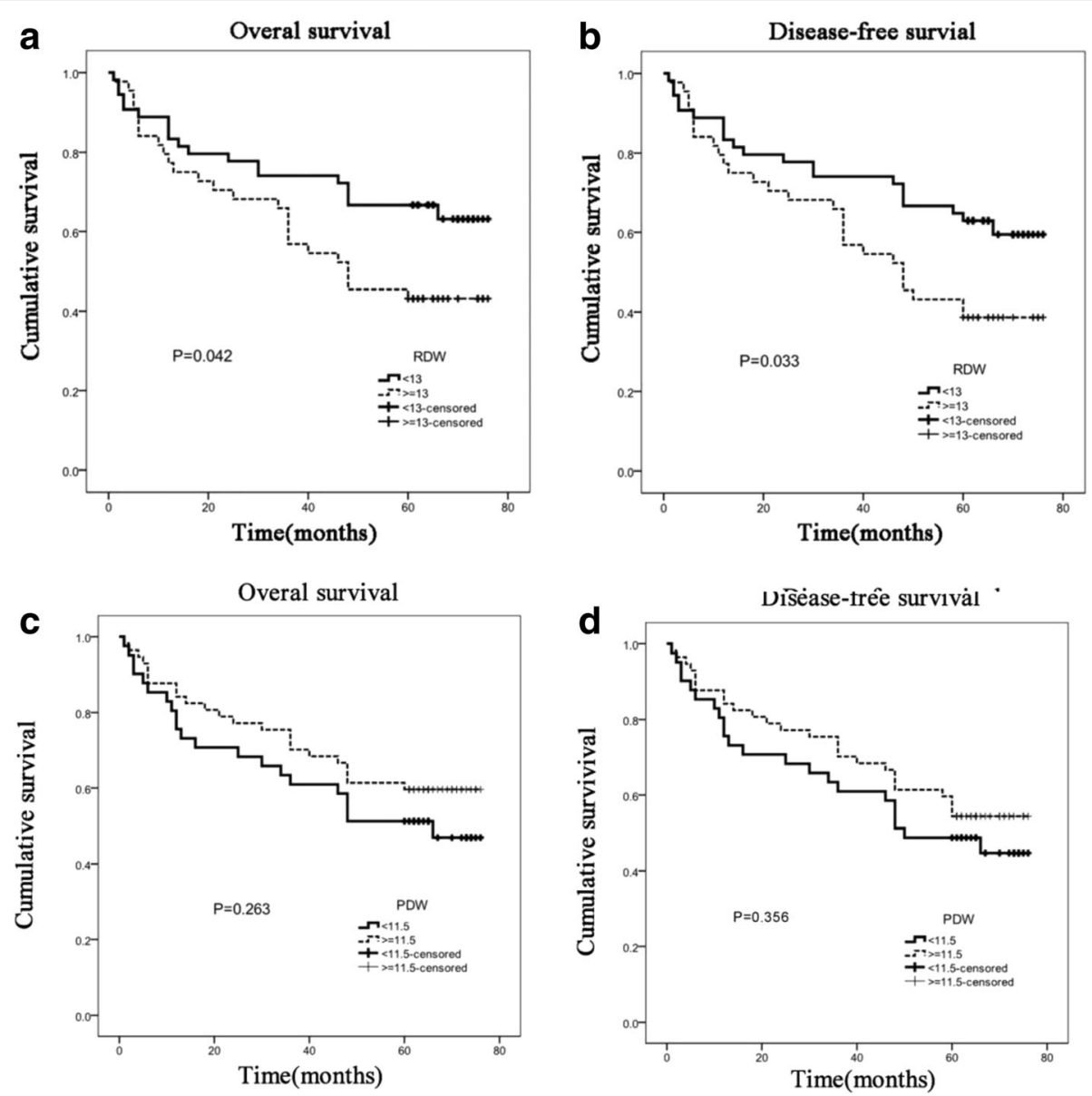

Fig. 3 Kaplan-Meier survival curves stratified by RDW and PDW in 227 patients with GC. a Kaplan-Meier curves for OS by RDW in all GC, $P=0.042$. b Kaplan-Meier curves for DFS by RDW in all GC, $P=0.033$. c Kaplan-Meier curves for OS by PDW in all GC. $\mathbf{d}$ Kaplan-Meier curves for DFS by PDW in all GC. $P$ values were determined using the log-rank test

\section{Associations of RDW and PDW with prognosis of GC}

To verify whether the RDW and PDW were the independent prognosis factors of GC, univariate and multivariate survival analysis for OS and DFS was performed. The analysis for 227 GC was exhibited in Table 3, a univariate analysis showed that tumor diameter $(P=0.001)$, degree of differentiation $(P=0.041)$, depth of tumor $(P<0.001)$, lymph node metastasis $(P<0.001)$, distant metastasis $(P=0.026)$, pStage $(P<0.001)$ and CA199 $(P=0.017)$ were significantly associated with OS. Moreover, a similar association with respect to DFS was also observed for the RDW $(P=0.044)$, age $(P=0.044)$, tumor diameter $(P=0.001)$, depth of tumor $(P<0.001)$, lymph node metastasis $(P<0.001)$, pStage $(P<0.001)$ and CA199 $(P=0.009)$. All significant prognostic factors tested by univariate analysis were evaluated by multivariate analysis. Depth of tumor and pStage were independent risk factors of OS $(P=0.006$ and $P=0.004)$ and DFS $(P=0.010$ and $P=0.005)$ in GC. For 164 patients with early stage GC, univariate and multivariate survival analysis showed that RDW and PDW can act as independent prognostic factors for DFS $(P=0.028$ and $P=0.020)$, but no significant factor was found for OS (Table 4).

\section{Discussion}

Cancer is a leading cause of death in both more and less economically developed countries. In recent years, the fact that cancer may act as either a cause or a result of chronic inflammation aroused the attention to the connection between inflammation and malignancies [18]. Studies have demonstrated that the cancer-associated inflammation plays an important role in carcinogenesis and tumor progression $[19,20]$. The possible mechanism may be that inflammation was associated with malnutrition, immune dysfunction, platelet activation, angiogenesis and activation of cytokines [21, 22]. Although the general factors of GC including tumor stage, lymph node metastases, and lymphatic vessel invasion have been used clinically for patient risk-stratification and the 

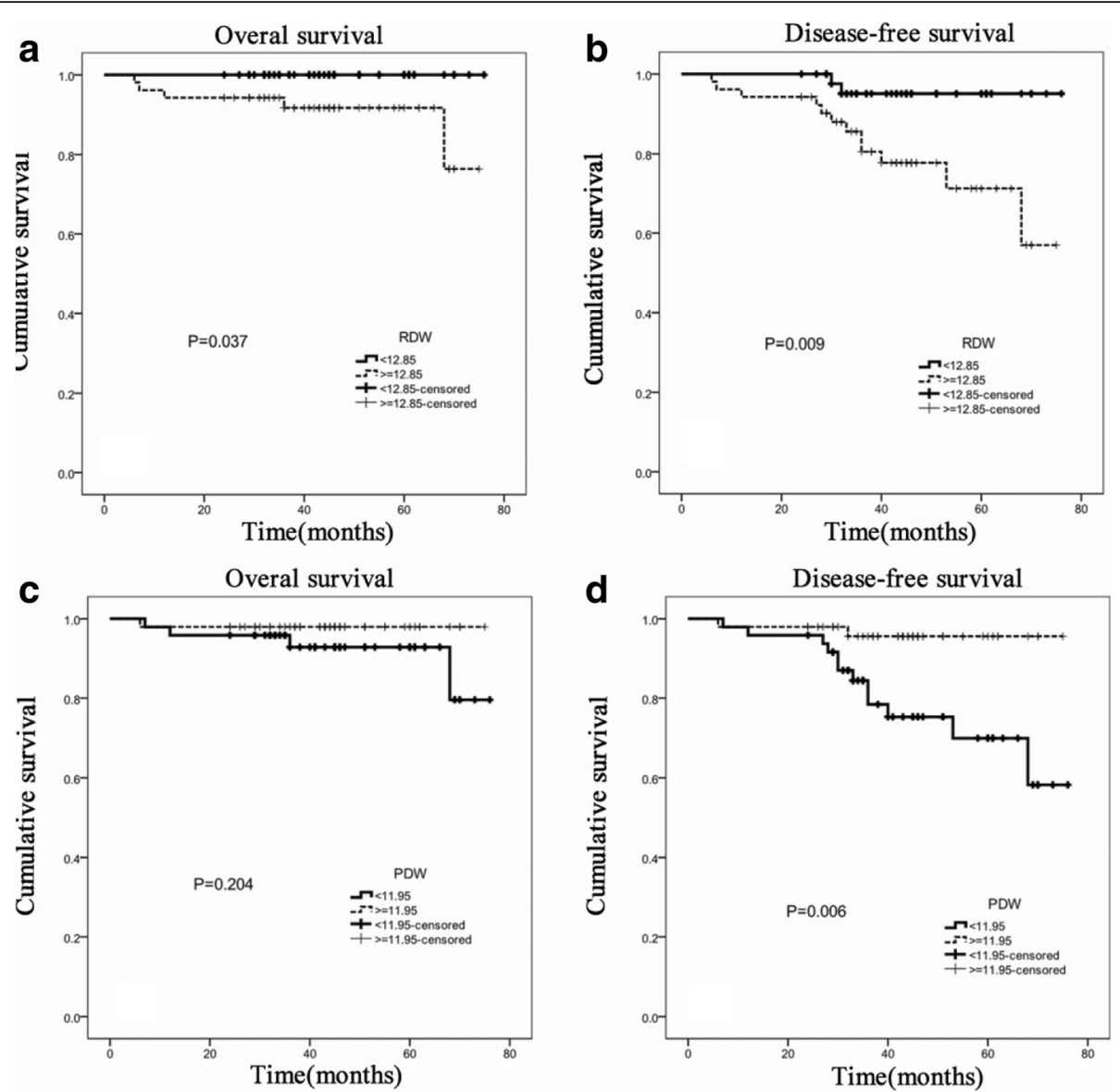

Fig. 4 Kaplan-Meier survival curves stratified by RDW and PDW in 164 patients with GC at early stage. a Kaplan-Meier curves for OS by RDW in early stage GC. b Kaplan-Meier curves for DFS by RDW in early stage GC. c Kaplan-Meier curves for OS by PDW in early stage GC. $\mathbf{d}$ Kaplan-Meier curves for DFS by PDW in early stage GC. P values were determined using the log-rank test

guidance of therapeutic strategy, the complexity of clinical conditions of cancer patients prompts us to search for more appropriate biomarkers to evaluate the patient's general condition for therapeutic and prognostic purposes. Despite scientific efforts, there are few suitable serum/plasma biomarkers of GC, which have high sensitivity and specificity for the screening or surveillance of this malignancy.

Previous studies have demonstrated that hematologic parameters including NLR, PLR, MPV, RDW were significantly correlated with many malignant tumors, such as colorectal cancer, prostate cancer, esophageal cancer and breast cancer [23-26]. Therefore, in the present study, we detected whether the preoperative RDW and PDW value could distinguish the patients of GC and early GC from the healthy controls. In addition, we analyzed the association of RDW, PDW with the clinicopathological features of patients with GC. Furthermore, we evaluated the predictive effect of RDW and PDW on progression and prognosis of GC.
RDW, which is a measure of heterogeneity in erythrocyte size, is a sensitive and specific indicator of iron deficiency anaemia. Recently, there has been growing evidence that high RDW, frequently associated with inflammation and oxidative stress, increases overall and disease-specific mortality in patients with chronic or progressive inflammation diseases [10, 11, 27, 28]. Many studies have shown that it was closely related to the other inflammation markers such as CRP, IL-6 and TNF- $\alpha[27,29]$. It was also shown that RDW increased in the inflammatory intestinal disease in which chronic and active inflammation increased [10]. Emerging evidence has suggested that RDW might can be used as a marker for diagnosis or prognosis in various solid cancers. Moreover, most studies focused on RDW as an independent predictor of cancer survival. Seretis et al. [12] showed that RDW was significantly higher in patients with breast cancer compared to the patients with fibroadenomas and had a high correlation with the size of primary tumor, the number of metastatic axillary lymph glands and overexpression of HER2. Warwick et al. [30] 
Table 3 Univariate and multivariate survival analysis results of 227 patients with GC

\begin{tabular}{|c|c|c|c|c|c|c|c|c|}
\hline \multirow{2}{*}{$\begin{array}{l}\text { Clinicopathological } \\
\text { feature }\end{array}$} & \multicolumn{2}{|l|}{ Univariate $(\mathrm{a})$} & \multicolumn{2}{|l|}{ Multivariate $^{\mathrm{b}}(\mathrm{OS})$} & \multicolumn{2}{|l|}{ Univariate $^{\mathrm{a}}(\mathrm{DFS})$} & \multicolumn{2}{|l|}{ Multivariate $^{\mathrm{b}}(\mathrm{DFS})$} \\
\hline & $\mathrm{HR}(95 \% \mathrm{Cl})$ & $P$ value & $\mathrm{HR}(95 \% \mathrm{Cl})$ & $P$ value & HR $(95 \%$ Cl) & $P$ value & $\mathrm{HR}(95 \% \mathrm{Cl})$ & $P$ value \\
\hline RDW(<13/ $\geq 13)$ & $1.801(0.985-3.291)$ & 0.056 & & & $1.807(1.015-3.217)$ & 0.044 & & \\
\hline $\operatorname{PDW}(<11.5 / \geq 11.5)$ & $0.701(0.385-1.275)$ & 0.244 & & & $0.754(0.425-1.337)$ & 0.333 & & \\
\hline Gender(Male/Female) & $0.764(0.355-1.648)$ & 0.493 & & & $0.908(0.452-1.827)$ & 0.787 & & \\
\hline Age $(<60 / \geq 60)$ & $1.541(0.844-2.814)$ & 0.160 & & & $1.535(0.863-2.730)$ & 0.044 & & \\
\hline Tumor diameter $(\leq 4 />4)$ & $2.890(1.553-5.375)$ & 0.001 & & & $2.633(1.465-4.731)$ & 0.001 & & \\
\hline $\begin{array}{l}\text { Differentiation } \\
\text { (Well/Moderate/ Poor) }\end{array}$ & $1.968(1.027-3.772)$ & 0.041 & & & $1.650(0.926-2.941)$ & 0.089 & & \\
\hline $\begin{array}{l}\text { Depth of tumor } \\
(\mathrm{T} 1+\mathrm{T} 2 / \mathrm{T} 3+\mathrm{T} 4)\end{array}$ & $2.169(1.613-2.916)$ & $<0.001$ & $1.722(1.170-2.535)$ & 0.006 & 2.097 (1.569-2.802) & $<0.001$ & $1.655(1.130-2.422)$ & 0.010 \\
\hline $\begin{array}{l}\text { Lymph node metastasis } \\
\text { (NO/N1 + N2 + N3) }\end{array}$ & $5.548(2.335-13.181)$ & $<0.001$ & & & $4.548(2.118-9.763)$ & $<0.001$ & & \\
\hline $\begin{array}{l}\text { Distance metastasis } \\
\text { (M0/M1) }\end{array}$ & $2.403(1.112-5.193)$ & 0.026 & & & $2.137(0.996-4.584)$ & 0.051 & & \\
\hline pStage(I + II/III + IV) & 7.841 (3.075-19.994) & $<0.001$ & $4.311(1.591-11.682)$ & 0.004 & 6.179 (2.755-13.858) & $<0.001$ & $3.517(1.470-8.413)$ & 0.005 \\
\hline $\mathrm{CEA}(\leq 5 />5)$ & $1.240(0.552-2.788)$ & 0.602 & & & $1.116(0.500-2.492)$ & 0.789 & & \\
\hline CA125( $\leq 35 />35)$ & $2.606(0.353-19.240)$ & 0.348 & & & $2.606(0.353-19.240)$ & 0.348 & & \\
\hline CA199( $\leq 39 />39)$ & $2.405(1.173-4.930)$ & 0.017 & & & $2.478(1.249-4.917)$ & 0.009 & & \\
\hline
\end{tabular}

Abbreviations: OS overall survival, DFS disease-free survival, $H R$ hazard ratio, $C /$ confidence interval, $R D W$ red blood cell distribution width,

CEA carcinoembryonic antigen, CA125 carbohydrate antigen 125, CA199 carbohydrate antigen 199

a Performed using the Kaplan-Meier analysis model and the log-rank test; values of $P<0.05$ in the univariate analysis were entered into a multivariate analysis

${ }^{b}$ performed using Cox proportional hazards models with the forward likelihood method

found that preoperative RDW in patients undergoing pulmonary resections for non-small-cell lung cancer could predict mortality and long-term survival. Potential mechanisms of elevated RDW in cancer patients may be that carcinogenesis is usually accompanied by increased inflammation, which causes inhibited response to erythropoietin, reduced iron release from reticuloendothelial macrophages, and shortened red blood cell survival through relevant inflammatory markers. In addition, RDW was found to be associated with

Table 4 Univariate and multivariate survival analysis results of 164 patients with GC at early stage

\begin{tabular}{|c|c|c|c|c|c|c|}
\hline \multirow[t]{2}{*}{ Variables } & \multicolumn{2}{|l|}{ Univariate $^{\mathrm{a}}$ (OS) } & \multicolumn{2}{|l|}{ Univariate $^{\mathrm{a}}$ (DFS) } & \multicolumn{2}{|l|}{ Multivariate $^{\mathrm{b}}(\mathrm{DFS})$} \\
\hline & $\overline{\mathrm{HR}(95 \% \mathrm{Cl})}$ & $P$ value & $\mathrm{HR}(95 \% \mathrm{Cl})$ & $P$ value & $\mathrm{HR}(95 \% \mathrm{Cl})$ & $P$ value \\
\hline $\operatorname{RDW}(<12.85 / \geq 12.85)$ & $57.198(0.042-7.805 E 4)$ & 0.272 & $5.776(1.292-25.821)$ & 0.022 & $5.346(1.195-23.917)$ & 0.028 \\
\hline $\operatorname{PDW}(<11.95 / \geq 11.95)$ & $0.265(0.029-2.387)$ & 0.236 & $0.158(0.035-0.707)$ & 0.016 & $0.170(0.038-0.761)$ & 0.020 \\
\hline Gender(Male/Female) & $1.526(0.158-14.733)$ & 0.715 & $2.983(0.973-9.150)$ & 0.056 & & \\
\hline Age $(<60 / \geq 60)$ & $2.264(0.242-21.168)$ & 0.474 & $1.145(0.378-3.470)$ & 0.811 & & \\
\hline Tumor diameter $(\leq 4 />4)$ & $0.046(0.000-1.144 \mathrm{E} 7)$ & 0.754 & $2.507(0.318-19.758)$ & 0.383 & & \\
\hline $\begin{array}{l}\text { Differentiation } \\
\text { (Well/Moderate/ Poor) }\end{array}$ & $2.384(0.487-11.664)$ & 0.284 & $0.717(0.334-1.540)$ & 0.394 & & \\
\hline $\begin{array}{l}\text { Lymph node metastasis } \\
\text { (NO/N1 + N2 + N3) }\end{array}$ & $1.460(0.201-10.620)$ & 0.708 & $1.706(0.513-5.671)$ & 0.383 & & \\
\hline $\begin{array}{l}\text { Distance metastasis } \\
\text { (M0/M1) }\end{array}$ & $0.047(0.000-1.212 \mathrm{E} 9)$ & 0.803 & $0.047(0.000-1.401 \mathrm{E} 4)$ & 0.634 & & \\
\hline pStage $(I+I / I I I+\mid I V)$ & $2.243(0.250-20.161)$ & 0.471 & $1.478(0.330-6.615)$ & 0.609 & & \\
\hline$C E A(\leq 5 />5)$ & $0.045(0.000-2.044 E 14)$ & 0.602 & $0.046(0.000-3.688 \mathrm{E} 4)$ & 0.657 & & \\
\hline CA125( $\leq 35 />35)$ & $1.000(0.000-2584.626)$ & 1.000 & $0.046(0.000-4.070 E 7)$ & 0.770 & & \\
\hline CA199(<39/>39) & $0.039(0.000-5.365 E 7)$ & 0.762 & $0.042(0.000-1.509 E 4)$ & 0.627 & & \\
\hline
\end{tabular}

Abbreviations: OS overall survival, DFS disease-free survival, $H R$ hazard ratio, $C l$ confidence interval, $R D W$ red blood cell distribution width, CEA carcinoembryonic antigen, CA125 carbohydrate antigen 125, CA199 carbohydrate antigen 199

${ }^{a}$ Performed using the Kaplan-Meier analysis model and the log-rank test; values of $P<0.05$ in the univariate analysis were entered into a multivariate analysis

${ }^{b}$ performed using Cox proportional hazards models with the forward likelihood method 
malnutrition, which has been shown to be correlated to lower response to treatment, poorer prognosis and quality of life [31, 32].

The first association between hypercoagulability and malignancy traces back to the observations made by Trousseau in 1865, yet today thromboembolism is one the most common causes of death in cancer patients [33]. Activated platelet leads to hypercoagulability. Platelet can be activated by inflammatory factors such as interleukin-6, and elevated platelet in peripheral blood is associated to the development of many cancers [34-36]. And that the induction of platelet synthesis leads to not only the change of platelet count but also function and physiology [15]. PDW is a direct flow cytometric measurement of platelet cell volume and clinicians pay less attention than platelet count. PDW seems to be a more specific indicator of platelet activation than mean platelet volume (MPV), since it was not elevated during single platelet distention caused by platelet swelling [37]. As we mention above, the systemic inflammatory response is associated with coagulation processes, although the precise mechanisms that underlie this response, as well as the interaction between coagulation, inflammation, and carcinogenesis remain obscure.

Through the comparison between groups, we found that the values of RDW in patients with GC were significantly higher than those in healthy controls and the PDW values in GC were significantly lower than those in controls. In addition to, in order to validate whether the RDW and PDW can become the differential diagnosis indicators of early GC, we collected 164 patients with early GC to compare with the healthy controls, finding that the differences were also significant. The results enlightened us that the RDW and PDW can be used as screening indicators of GC. Wang FM et al. [38] reported that the RDW values were significantly higher in patients with renal cell carcinoma than those with controls, which was consistent with our result. However for PDW,although several clinical studies have demonstrated that PDW was elevated in patients with chronic inflammatory and various carcinomas $[14,39]$, other studies have support our findings. Chronic inflammatory process in patients with inflammatory bowel diseases (IBD) results in increasing in the number of blood platelets and changing in their activation and morphological parameters, and PDW was significantly lower in active phase of Ulcerative colitis and Crohn's disease groups than remission phase [40]. Kurtoglu et al. [41] found that decreased PDW values were significantly associated with endometrium cancer. This suggests that the reduction of PDW may be related to the progression or activation of disease, rather than simply related to a disease.

We investigated the relationships between RDW, PDW and cliniclpathological features and detected that a higher RDW was significantly associated with advanced disease such as older age, a larger tumor diameter, deeper tumor infiltration, and Lymph node metastasis while a lower PDW was significantly associated with advanced condition such as male, older age, a larger tumor diameter, deeper tumor infiltration, elevated CEA and CA125. The results above indicated that increased RDW and decreased PDW can be used as indicators of malignant progression in GC.

We carried out the follow-up and analyzed the survival rates in patients with GC and early GC. A high preoperative RDW predicted respectively worse OS and poorer DFS in patients with GC and early GC while a decreased PDW group only exhibited a poor DFS than low group in early GC. The results testified that RDW and PDW could be used to estimate the survival rates of the patients with GC. Furthermore, we conducted univariate and multivariate analysis to predict the independent factors of GC. A high RDW was significantly associated with poor DFS and had a borderline relationship with OS in univariate analysis. Although high RDW lost its independent prognostic significance for OS and DFS in multivariate analysis, it still offered considerable information on RDW for clinical prognosis. In addition, increased RDW or decreased PDW was significantly connected with worse DFS in univariate and multivariate analysis, which indicated that the RDW and PDW could be used as independent prognostic indicators of early stage GC.

An assessment of RDW and PDW levels to predict clinical outcomes in patients with GC has advantages. It can be acquired immediately when the patient is suspected of GC to assess the patient's general condition objectively such as malnutrition and abnormal coagulation state, contribute to diagnosis and prognosis evaluation. However, several limitations need to be noted in this study. First, the major limitation of the present study is the determination of the cutoff values. The current literatures confirmed the optimal cutoff values for RDW and PDW according to ROC curves, median value or based on previous studies. We also analyzed the survival for GC using the cutoff values according to ROC and previous studied, but no correspondingly significant difference was detected. Second, the sample size was small,which may reflect a selection bias and be less persuasive; Third, our study was a retrospective study, so there may be potential bias and inaccuracy in data collection as in most retrospectively designed studies.

\section{Conclusions}

In conclusion, as available and convenient biomarkers, the RDW and PDW have diagnostic power and can discriminate patients with GC and early stage GC from the healthy controls. In addition, the RDW and PDW can be used as significant indicators for progression and prognosis of GC. 
But it must be noted that measurement of single biomarkers identified far lack sufficient sensitivity and specificity may not always accurately provide information alone, which may be affected by many factors. It is likely that multiple markers like RDW and PDW will need to be employed simultaneously. Nevertheless, there is a need for prospective studies to understand the mechanisms underlying the alterations of RDW and PDW in carcinogenesis and chronic inflammatory conditions.

\section{Abbreviations}

CA199: Carbohydrate antigen 199; CBC: Complete blood count;

CEA: Carcinoembryonic antigen; DFS: Disease-free survival; GC: Gastric cancer; IBD: Inflammatory bowel diseases; OS: Overall survival; PDW: Platelet distribution width; RDW: Red distribution width

\section{Acknowledgments}

The authors wish to thank the staff of Pathology department, Shandong Provincial Hospital Affiliated to Shandong University for their help in data collection.

\section{Funding}

This study was supported by grants from National Natural Science Foundation of China (81000731) and the promotive research fund for excellent young and middle-aged scientists of Shandong Province (BS2010YY045).

\section{Availability of data and materials}

The datasets during and/or analysed during the current study available from the corresponding author on reasonable request.

\section{Authors' contributions}

Concepts and design of the study: YJ, ZL; data acquisition, follow up and statistical analyses: SC, FH, YX, TQ; analysis and interpretation of the data, manuscript preparation, editing and revision: SC, FH, YW. All authors read and approved the final manuscript.

\section{Ethics approval and consent to participate}

Approval for the study was granted by the Ethics Committee of the Shandong Provincial Hospital Affiliated to Shandong University with written informed consents from all participants complianced with the guidelines of the Declaration of Helsinki.

\section{Consent for publication}

Not applicable

\section{Competing interests}

The authors declare that they have no competing interests.

\section{Publisher's Note}

Springer Nature remains neutral with regard to jurisdictional claims in published maps and institutional affiliations.

Received: 26 January 2017 Accepted: 17 November 2017 Published online: 20 December 2017

\section{References}

1. Ferlay J, Shin HR, Bray F, Forman D, Mathers C, Parkin DM. Estimates of worldwide burden of cancer in 2008: GLOBOCAN 2008. Int J Cancer. 2010; 127:2893-917.

2. Jemal A, Bray F, Center MM, Ferlay J, Ward E, Forman D. Global cancer statistics. CA Cancer J Clin. 2011;61:69-90.

3. Wagner AD, Grothe W, Haerting J, Kleber G, Grothey A, Fleig WE. Chemotherapy in advanced gastric cancer: a systematic review and metaanalysis based on aggregate data. J Clin Oncol. 2006;24:2903-9.

4. Fock KM. Review article: the epidemiology and prevention of gastric cancer. Aliment Pharmacol Ther. 2014:40:250-60.

5. Pietrzyk L, Torres A, Maciejewski R, Torres K. Obesity and obese-related chronic low-grade inflammation in promotion of colorectal cancer development. Asian Pac J Cancer Prev. 2015;16:4161-8.
6. Kim DK, SY O, Kwon HC, Lee S, Kwon KA, Kim BG, Kim SG, Kim SH, Jang JS, Kim MC, et al. Clinical significances of preoperative serum interleukin-6 and C-reactive protein level in operable gastric cancer. BMC Cancer. 2009;9:155.

7. Fichtner-Feigl S, Kesselring R, Strober W. Chronic inflammation and the development of malignancy in the Gl tract. Trends Immunol. 2009;36:451-9.

8. Hanahan D, Weinberg RA. Hallmarks of cancer: the next generation. Cell. 2011;144:646-74.

9. Forhecz Z, Gombos T, Borgulya G, Pozsonyi Z, Prohaszka Z, Janoskuti L. Red cell distribution width in heart failure: prediction of clinical events and relationship with markers of ineffective erythropoiesis, inflammation, renal function, and nutritional state. Am Heart J. 2009;158:659-66.

10. Yesil A, Senates E, Bayoglu IV, Erdem ED, Demirtunc R, Kurdas OA. Red cell distribution width: a novel marker of activity in inflammatory bowel disease. Gut Liver. 2011;5:460-7.

11. Gunebakmaz O, Kaya MG, Duran M, Akpek M, Elcik D, Eryol NK. Red blood cell distribution width in 'non-dippers' versus 'dippers'. Cardiology. 2012;123:154-9.

12. Seretis C, Seretis F, Lagoudianakis E, Gemenetzis G, Salemis NS. Is red cell distribution width a novel biomarker of breast cancer activity? Data from a pilot study. J Clin Med Res. 2013;5:121-6.

13. Koma Y, Onishi A, Matsuoka H, Oda N, Yokota N, Matsumoto Y, Koyama M, Okada N, Nakashima N, Masuya D, et al. Increased red blood cell distribution width associates with cancer stage and prognosis in patients with lung cancer. PLoS One. 2013;8:e80240.

14. Bath PM, Missouris CG, Buckenham T, McGregor GA. Increased platelet volume and platelet mass in patients with atherosclerotic renal artery stenosis. Clin Sci. 1994;87:253-7.

15. Bath PM, Butterworth RJ. Platelet size: measurement, physiology and vascular disease. Blood Coagul Fibrinolysis. 1996;7:157-61.

16. Santimone I, Di Castelnuovo A, De Curtis A, Spinelli M, Cugino D, Gianfagna F, Zito F, Donati MB, Cerletti C, de Gaetano G, lacoviello L, MOLI-SANI Project Investigators. White blood cell count, sex and age are major determinants of heterogeneity of platelet indices in an adult general population: results from the MOLI-SANI project. Haematologica. 2011;96: $1180-8$

17. Washington K. 7th edition of the AJCC cancer staging manual: stomach. Ann Surg Oncol. 2010;17:3077-9.

18. Kemal Y, Demirag G, Bas B, Onem S, Teker F, Yucel I. The value of red blood cell distribution width in endometrial cancer. Clin Chem Lab Med. 2015:53:823-7.

19. Mantovani A, Allavena P, Sica A, Balkwill F. Cancer-related inflammation. Nature. 2008:454:436-44.

20. Pollard JW. Tumour-educated macrophages promote tumour progression and metastasis. Nat Rev Cancer. 2004:4:71-8.

21. Balkwill F, Mantovani A. Inflammation and cancer: back to Virchow? Lancet. 2001;357:539-45.

22. Schreiber RD, Old LJ, Smyth MJ. Cancer immunoediting: integrating immunity's roles in cancer suppression and promotion. Science. 2011;331: $1565-70$.

23. Wang $L$, Sheng $L$, Liu P. The independent association of platelet parameters with overall survival in pancreatic adenocarcinoma receiving intensitymodulated radiation therapy. Int J Clin Exp Med. 2015;8:21215-21.

24. Hirahara N, Matsubara T, Kawahara D, Mizota Y, Ishibashi S, Tajima Y. Prognostic value of hematological parameters in patients undergoing esophagectomy for esophageal squamous cell carcinoma. Int J Clin Oncol. 2016;21:909-19

25. Zou ZY, Liu HL, Ning N, Li SY, XH DU, Li R. Clinical significance of pre-operative neutrophil lymphocyte ratio and platelet lymphocyte ratio as prognostic factors for patients with colorectal cancer. Oncol Lett. 2016;11:2241-8.

26. Okuturlar Y, Gunaldi M, Tiken EE, Oztosun B, Inan YO, Ercan T, Tuna S, Kaya $\mathrm{AO}$, Harmankaya $\mathrm{O}$, Kumbasar A. Utility of peripheral blood parameters in predicting breast cancer risk. Asian Pac J Cancer Prev. 2015;16:2409-12.

27. Karabulut A, Uzunlar B. Correlation between red cell distribution width and coronary ectasia in the acute myocardial infarction. Clin Appl Thromb Hemost. 2012;18:551-2.

28. Albayrak S, Zengin K, Tanik S, Bakirtas H, Imamoglu A, Gurdal M. Red cell distribution width as a predictor of prostate cancer progression. Asian Pac J Cancer Prev. 2014;15:7781-4.

29. Agarwal S. Red cell distribution width, inflammatory markers and cardiorespiratory fitness: results from the National Health and Nutrition Examination Survey. Indian Heart J. 2012;64:380-7. 
30. Warwick R, Mediratta NM, Shackcloth M, McShane Shaw J, Poullis M. Preoperative red cell distribution width in patients undergoing pulmonary resections for non-small-cell lung cancer. Eur J Cardiothorac Sur. 2014;45:108-13.

31. McMillan DC. Systemic inflammation, nutritional status and survival in patients with cancer. Curr Opin Clin Nutr Metab Care. 2009;12:223-6.

32. Hebuterne X, Lemarie E, Michallet M, de Montreuil CB, Schneider SM, Goldwasser F. Prevalence of malnutrition and current use of nutrition support in patients with cancer. JPEN J Parenter Enteral Nutr. 2014;38:196-204.

33. Loreto MF, De Martinis M, Corsi MP, Modesti M, Ginaldi L. Coagulation and cancer: implications for diagnosis and management. Pathol Oncol Res. 2000; 6:301-12.

34. Berstein LM, Tsyrlina EV, Semiglazov VF, Kovalenko IG, Gamayunova VB, Evtushenko TP, Ivanova OA. Hormone-metabolic status in moderately smoking breast cancer patients. Acta Oncol. 1997;36:137-40.

35. Chlebowski RT, Heber D. Metabolic abnormalities in cancer patients: carbohydrate metabolism. Surg Clin North Am. 1986;66:957-68.

36. Huang $S$, Chong N, Lewis NE, Jia W, Xie G, Garmire LX. Novel personalized pathway-based metabolomics models reveal key metabolic pathways for breast cancer diagnosis. Genome Med. 2016;31:34.

37. Vagdatli E, Gounari E, Lazaridou E, Katsibourlia E, Tsikopoulou F, Labrianou I. Platelet distribution width: a simple, practical and specific marker of activation of coagulation. Hippokratia. 2010;14:28-32.

38. Wang FM, Xu G, Zhang Y, Ma LL. Red cell distribution width is associated with presence, stage, and grade in patients with renal cell carcinoma. Dis Markers. 2014;2014:860419.

39. Ma X, Wang Y, Sheng H, Tian W, Qi Z, Teng F, Xue FJ. Prognostic significance of thrombocytosis, platelet parameters and aggregation rates in epithelial ovarian cancer. J Obstet Gynaecol Res. 2014;40:178-83.

40. Ozturk ZA, Dag MS, Kuyumcu ME, Cam H, Yesil Y, Yilmaz N, Aydinli M, Kadayifci A, Kepekci Y. Could platelet indices be new biomarkers for inflammatory bowel diseases? Eur Rev Med Pharmacol Sci. 2013;17:334-41.

41. Kurtoglu E, Kokcu A, Celik H, Sari S, Tosun M. Platelet indices may be useful in discrimination of benign and malign endometrial lesions, and early and advanced stage endometrial cancer. Asian Pac J Cancer Prev. 2015;16:5397-400.

\section{Submit your next manuscript to BioMed Central and we will help you at every step:}

- We accept pre-submission inquiries

- Our selector tool helps you to find the most relevant journal

- We provide round the clock customer support

- Convenient online submission

- Thorough peer review

- Inclusion in PubMed and all major indexing services

- Maximum visibility for your research

Submit your manuscript at www.biomedcentral.com/submit

C) Biomed Central 